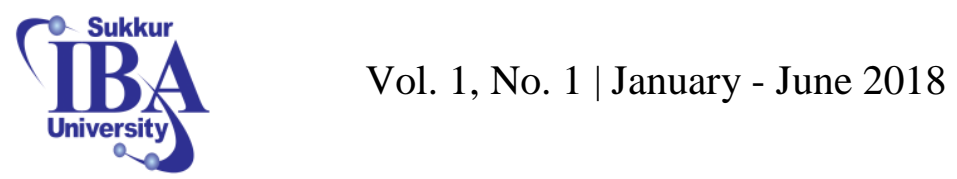

\title{
Automatic Positioned Controller Parabolic solar Dish Prototype
}

\author{
Asif A.Rahimoon ${ }^{1}$, Izhar A.Sohu ${ }^{1}$, M.Ishaque Junejoํㅜ, Ali Abbas ,S.Nawaz \\ Shah $^{1}$,Arslan Ahmed Sohu ${ }^{2}$
}

\begin{abstract}
:
This paper discusses the development of dual axis parabolic dish tracker application for automatized position power system. This prototype tackles solar light in solar sterling design system or concentrated photovoltaic design by implementation of digitalize control circuit to enhance Concentrating solar power and Concentrating photovoltaic applications. A normally $121.92 \mathrm{~cm}$ dish is designed with $\mathrm{H}$-bridge controller technique \& Slew drive actuator mode to capture solar irradiances. The surface of dish is polished with 12 aluminum bars to concentrate the solar irradiance in one reflective axis. Economic justification for Pakistan's industries would be possible if these automated based renewable prototypes are promoted in market in compare of single PV panel. This prototype controls the all weather conditions, utilizing real time flexible timing control strategy and photoelectric tracking scheme to provide cost effective product for industrial power generation applications. This locally adaptive material based prototype encouraged the result about $33 \%$ efficient with compared to photovoltaic panel.
\end{abstract}

Keywords: Pakistan Energy future; Solar concentrator; Thermal energy utilization.

\section{Introduction}

The world-wide rate of countries are utilizing decentralized power system to maintain the energy demand with small power energy system. These mini energy systems can be fabricated with renewable sources such as solar cooker, solar geyser, solar hydrogen productive devices and parabolic solar dish collectors [1, 2]. Utilization of parabolic reflector is proven to be effective through observation of different researchers that worked on heat collector by designing parabolic solar dish [3, 4]. The solar heat collectors are more reliable in operation when the suitable tracking scheme is installed with it. The different heat collectors are used from ancient times in bucolic sites as in 212 BC, Archimedes used sun light to burn roman fleet and in 10th century Ibn Sahl worked on parabolic mirror. The same trend is followed by new researchers on parabolic solar dish to capture heat and dispatch an economical and optimized prototype in market with different applications [5, 6, 7]. In proposed prototype the solar dish is fabricated with aluminum glass that is integrated with controller scheme of tracking with concerned measurement of Azimuth angle to gain efficient sun-light. As by researcher there are different scenarios of designing this prototype on small level application to commercial based with alteration of its tracking control techniques such as PLC, SCADA \& Microcontroller to

${ }^{1}$ Faculty of Engineering, Science \& Technology (FEST), Indus University Karachi, Pakistan

${ }^{2}$ Department of Electrical Engineering,Sukkur IBA University,Sukkur,Pakisan

Corresponding Email: asif.ahmed@indus.edu.pk 
make parabolic heat collector efficient $[8,9$, 10].The integrated technology of this proposed system that is comprised of Arduino based dual axis tracker, $12 \mathrm{v}$ operating power window motors and sensor fault control strategy to maintain elevation and tilt angles smoothly enhance the future work of power industries.

\section{Proposed Dish Prototype}

For Pakistan, in rural or desert areas where sunlight appears invariably under seasonal mode, the desired system is proposed to capture the solar irradiance in regular and seasonal mode. With high reflective glass material the heat collection is merged under a single focal point of parabolic dish [11, 12]. The maintenance of solar dish elevation angle and tilt angle is done through LDR actuators and power window motors. The whole tracking of proposed parabolic solar dish is based on Arduino based chip board that regulate the whole system in optimal and efficient mode. The power running actuators get their startup power service from an external battery to improve the remedies of sensor mechanism. The designed automated dual axis tracking prototype is capable to attained high temperature applications like as hot water \& steam generation. As in previous research of dual axis the system rotates with their both operative modes which make the tracker slower in perception of heat measurement and sensor functioning so, to improve this state of sensor the optional mode is included in designed parabolic dish prototype that is tested at Indus University Karachi with Latitude $23.9207^{\circ} \mathrm{N}$ and Longitude $67.0882^{\circ} \mathrm{E}$ which gives you option to run your dish on single axis or both axis as suitable with your application area.

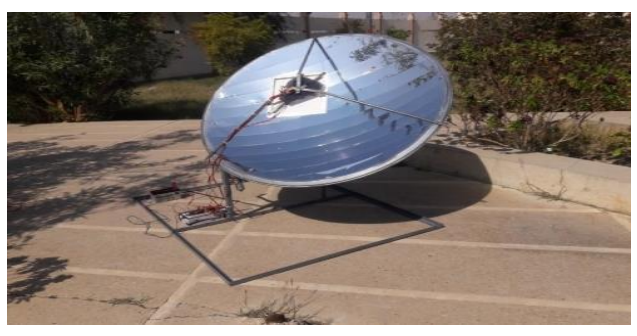

Fig. 1. Designed Prototype.

\section{Hardware Development}

The system is integrated with different parts to achieve the efficient output that is also calculated with some algorithms. The adoptive algorithm are included as parabola calculator2.0 for designing parameters of solar dish, solar angle meter for angle calculation of $\mathrm{X}$-axis \& Y-axis geometry, Arduino assembly for programming of controller chip, generalized equation are adopted with used of solar geometry tools that are as sun calculator $\&$ sun Earth tool for solar positioning and shadow effect rate. The arrangement of these integrated tools are shown in figure 3.

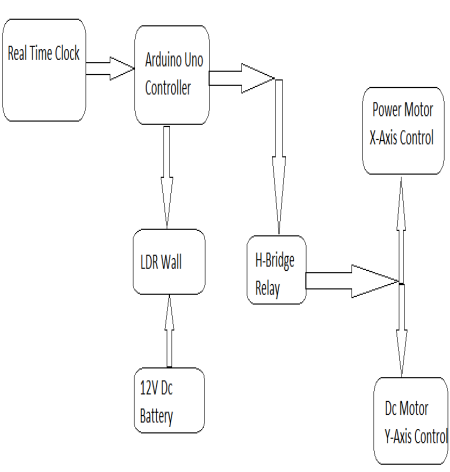

Fig. 2. Block Diagram.

\subsection{Parabolic solar Dish design}


TABLE I. Detailed sheet of dish.

\begin{tabular}{|c|c|c|c|}
\hline $\begin{array}{c}\text { Sr: } \\
\text { No. }\end{array}$ & Parameters & Values & Units \\
\hline 1 & Linear Diam. & 14 & $\mathrm{Ft}$ \\
\hline 2 & Diameter & 13.12 & $\mathrm{Ft}$ \\
\hline 3 & Depth & 2.24 & $\mathrm{Ft}$ \\
\hline 4 & Focal Length & 4.724 & $\mathrm{Ft}$ \\
\hline 5 & Volume & 4.28 & cubic $\mathrm{ft}$ \\
\hline 6 & F Length/Diam & 0.36 & $\mathrm{~N} / \mathrm{A}$ \\
\hline 7 & Area & 134.43 & $\mathrm{ft}^{2}$ \\
\hline
\end{tabular}

TABLE II. Automatic Tracking parameters.

\begin{tabular}{|l|l|}
\hline Tracking Control & \multicolumn{2}{|l|}{$\begin{array}{l}\text { Dualaxis Azimuth and elevation } \\
\text { algorithm }\end{array}$} \\
\hline Tracking & \multicolumn{1}{|c|}{$0.06^{0} \cong 1$ mrad } \\
\hline TrackingAccuracy & Arduino Uno based microcontroller \\
\hline ControlScheme & $180^{0}$ limiting switch \#4 \\
\hline Controlapparatus & $55^{\circ}$ limiting switch \#5 \\
\hline X-axis control Motorwith Pin\# & Relay Based Module \\
\hline Y-axis control Motorwith Pin\# & L298 module \\
\hline H-bridge & \\
\hline Motor Logical direction Controller &
\end{tabular}

\subsection{Sensor Configuration}

There are a lot of sensors used to run the trackers with opto-electronics technology. Here in this designed prototype we have installed LDR wall that will function with $12 \mathrm{v}$ output power. The designed wall is configured with $\mathrm{H}$-Bridge drive module and power motor rotation. As by research mostly implemented motor are servo motor and DC gear motors, but due to misalignment and speed management challenges this prototype is designed with $12 \mathrm{v}$ DC gear with slew controller technique and $12 \mathrm{v}$ wiper motor. Slew controller technique is installed to tilt the dish with optimum speed rate according with input rated pulse of PWM generator. Each motor gets its input from H-Bridge dual axis module which had internal 5v AVR and 2 Pulse generators.

\subsection{Arduino Controller}

Arduino is an open source digital it that assemble the software and hardware designed projects with less complexity. The Omega controller Arduino is computationally installed with this prototype which is easy to program with in running project as compared of other technologies. As this prototype needs simple management to provide an optimum output result so the easy configurable controller is used to track and run the parabolic solar tracker.

\subsection{Equations}

$$
\begin{aligned}
& H . A=\frac{\text { no.of minutes past midnight }}{\frac{4^{\circ}}{\min }} \\
& \text { b) change in hour } \\
& \text { angle }:=\frac{\sin \infty-\sin \delta \cdot \sin \emptyset}{\cos \delta . \cos \emptyset} \\
& \text { c) Declination angle } \\
& \text { D. } A= \\
& \sin ^{-1} *[\sin (\text { Earth Tilt angle }) * \\
& \sin (\text { earth eliptical position)] } \\
& \text { d) Altitude Angle }=\sin \propto=\sin \delta \text { * } \\
& \sin \emptyset+\cos \delta * \cos \omega * \cos \emptyset \\
& =\frac{\sin w \cdot \cos \delta}{\cos \alpha}
\end{aligned}
$$

\section{Parabolic Dish Working}

As concerned with dual axis solar heat collector from previous research work, different challenges were occur that are in sense of Cosine effect, Dish alignment, sensor actuation and MPPT technique(choice of controller). So, an automatic motorized control prototype is presented with $121.92 \mathrm{~cm}$ diameter dish to enhance the solar irradiance application. The working is performed at Karachi, Sindh Pakistan with coordinate location of Latitude $23.9207^{\circ} \mathrm{N}$ and Longitude $67.0882^{\circ} \mathrm{E}$.The whole implementation of solar designed dish with its all configured 
controller is accomplished on $4 * 4 \mathrm{ft}$ rectangular frame. The system perform its working when it get the input pulse from preset topology of controller to derive the motor in suitable direction either to tilt the dish or curve the dish with the help of DC-gear and power wiper motors. The output

is performed with placement of $20 \mathrm{w}$ Solar panel on parabolic dish.

TABLE III. Result Analysis.

\begin{tabular}{|c|c|c|c|c|c|c|c|c|c|c|}
\hline \multirow{2}{*}{$\begin{array}{c}\text { Change } \\
\text { in hour } \\
\text { angle }\end{array}$} & \multicolumn{2}{|c|}{ Angles measured } & \multirow{2}{*}{$\begin{array}{l}\text { Time } \\
\text { hour }\end{array}$} & \multicolumn{3}{|c|}{ Static solar PV } & \multicolumn{3}{|c|}{ Prototype Result } & \multirow{2}{*}{$\begin{array}{l}\text { Shadow } \\
\text { length(ft) }\end{array}$} \\
\hline & Altitude & Azimuth & & Voc & Isc & power & Voc & Isc & power & \\
\hline $12.49^{0}$ & $23.55^{0}$ & $130.19^{0}$ & 9am & 19.7 & 0.15 & 2.95 & 20.3 & 0.29 & 5.88 & 7.51 \\
\hline $25.09^{0}$ & $32.9^{0}$ & $141.91^{0}$ & $10 \mathrm{am}$ & 20.5 & 0.36 & 7.63 & 20.3 & 0.33 & 5.69 & 5.05 \\
\hline $34.29^{0}$ & $39.8^{0}$ & $157.02^{0}$ & $11 \mathrm{am}$ & 20.1 & 0.16 & 3.22 & 19.2 & 0.36 & 6.91 & 3.93 \\
\hline $38.67^{0}$ & $43.15^{0}$ & $175.18^{0}$ & $12 \mathrm{pm}$ & 20.1 & 0.34 & 8.33 & 19 & 0.69 & 13.11 & 3.51 \\
\hline $37.15^{0}$ & $42.04^{0}$ & $194.12^{0}$ & $1 \mathrm{pm}$ & 20.4 & 0.42 & 8.57 & 19 & 0.94 & 17.86 & 3.64 \\
\hline $30.19^{0}$ & $36.80^{0}$ & $210.9^{0}$ & $2 \mathrm{pm}$ & 20.2 & 0.43 & 8.68 & 20 & 0.67 & 13.4 & 4.39 \\
\hline $19.1^{0}$ & $28.5^{0}$ & $224.2^{0}$ & $3 \mathrm{pm}$ & 20 & 0.36 & 7.2 & 20.5 & 0.51 & 10.45 & 6.03 \\
\hline
\end{tabular}

\begin{tabular}{|c|c|c|c|c|c|c|c|c|c|c|c|}
\hline \multirow{3}{*}{$\begin{array}{l}\text { D } \\
\text { at } \\
\text { e }\end{array}$} & \multirow[t]{3}{*}{$\underset{\mathbf{e}}{\operatorname{Tim}}$} & \multirow{3}{*}{$\begin{array}{c}\text { Hou } \\
\mathbf{r} \\
\text { angl } \\
\mathbf{e}\end{array}$} & \multirow{3}{*}{$\begin{array}{c}\text { Chang } \\
\text { e in } \\
\text { H.A }\end{array}$} & \multirow{3}{*}{$\begin{array}{c}\text { Yearly } \\
\text { average } \\
\text { Solar } \\
\text { irradianc } \\
\text { e rate }\end{array}$} & \multicolumn{2}{|c|}{ Angles } & \multirow{3}{*}{$\begin{array}{c}\text { Shadow } \\
\text { length(ft } \\
\text { ) }\end{array}$} & \multicolumn{4}{|c|}{$\begin{array}{l}\text { Prototype LDR output } \\
\text { volts }\end{array}$} \\
\hline & & & & & \multirow{2}{*}{$\begin{array}{l}\text { Altitud } \\
\text { e angle }\end{array}$} & \multirow{2}{*}{$\begin{array}{l}\text { Azimuth } \\
\text { angle }\end{array}$} & & \multicolumn{2}{|c|}{$y$-axis } & \multicolumn{2}{|c|}{$\mathrm{x}$-axis } \\
\hline & & & & & & & & $\begin{array}{c}\text { LDR } \\
1\end{array}$ & $\begin{array}{c}\mathrm{LDR} \\
2\end{array}$ & $\begin{array}{c}\text { LDR } \\
3\end{array}$ & $\begin{array}{c}\mathrm{LDR} \\
4\end{array}$ \\
\hline \multirow{8}{*}{$\begin{array}{l}28 \\
. j a \\
n\end{array}$} & $\begin{array}{c}\text { Sunri } \\
\text { se }\end{array}$ & $0.46^{0}$ & & 1941 & & & & & & & \\
\hline & 9.am & $-45^{0}$ & $12.49^{0}$ & & $23.73^{0}$ & $130.10^{0}$ & 7.51 & $\begin{array}{c}0.72 \\
3\end{array}$ & $\begin{array}{c}0.56 \\
7\end{array}$ & $\begin{array}{c}3.63 \\
1\end{array}$ & $\begin{array}{c}3.78 \\
3\end{array}$ \\
\hline & $\begin{array}{c}10 \mathrm{a} \\
\mathrm{m}\end{array}$ & $-30^{0}$ & $25.09^{0}$ & & $33.15^{0}$ & $141.80^{0}$ & 5.05 & $\begin{array}{c}0.73 \\
3\end{array}$ & $\begin{array}{c}0.81 \\
6\end{array}$ & 3.9 & 3.78 \\
\hline & $\begin{array}{c}11 \mathrm{a} \\
\mathrm{m}\end{array}$ & $-15^{0}$ & $34.29^{0}$ & & $40.07^{0}$ & $157.02^{0}$ & 3.93 & $\begin{array}{c}3.21 \\
1\end{array}$ & $\begin{array}{c}2.29 \\
7\end{array}$ & $\begin{array}{c}3.91 \\
0\end{array}$ & $\begin{array}{c}3.69 \\
6\end{array}$ \\
\hline & $\begin{array}{c}12 \mathrm{p} \\
\mathrm{m}\end{array}$ & $0^{0}$ & $38.67^{0}$ & & $43.34^{0}$ & $175.27^{0}$ & 3.51 & $\begin{array}{c}4.88 \\
8\end{array}$ & $\begin{array}{c}4.94 \\
1\end{array}$ & 4.95 & 4.99 \\
\hline & $1 \mathrm{pm}$ & $15^{0}$ & $37.15^{0}$ & & $42.19^{0}$ & $194.28^{0}$ & 3.64 & $\begin{array}{c}3.83 \\
0\end{array}$ & $\begin{array}{c}3.91 \\
0\end{array}$ & $\begin{array}{c}4.98 \\
5\end{array}$ & $\begin{array}{c}4.99 \\
0\end{array}$ \\
\hline & $2 \mathrm{pm}$ & $30^{0}$ & $30.19^{0}$ & & $36.92^{0}$ & $211.11^{0}$ & 4.39 & 3.45 & 4.05 & $\begin{array}{c}4.97 \\
6\end{array}$ & $\begin{array}{c}4.98 \\
5\end{array}$ \\
\hline & $3 \mathrm{pm}$ & $45^{0}$ & $19.1^{0}$ & & $28.58^{0}$ & $224.4^{0}$ & 6.03 & 3.93 & $\begin{array}{c}3.84 \\
6\end{array}$ & $\begin{array}{c}4.94 \\
1\end{array}$ & $\begin{array}{c}4.89 \\
2\end{array}$ \\
\hline
\end{tabular}




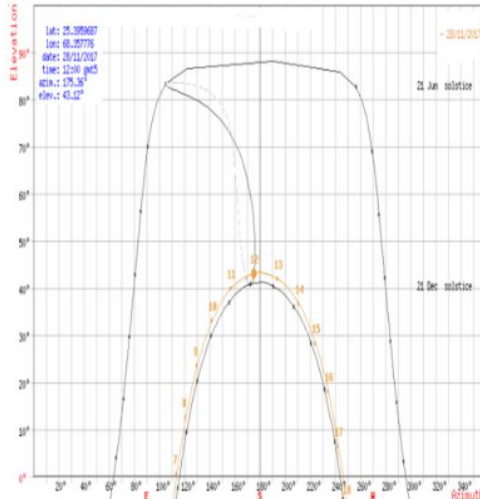

Fig. 3. Sun Position Graph.

\section{Conclusion}

The tariff of electric price is become inverse proportion to oil and fossil fuel tariff that creates that hazard effect of load shading. So to provide a sustainable tool with development of power optimized techniques, we have to promote renewable energy applications with help of technical expertise. In this research an innovative low cost parabolic dish is analyzed optically to compensate the MPPT tracking issues. The thermally analyzed result is obtained with hour angle formulae tools and flux meter that is about $210 \mathrm{w} / \mathrm{m}^{2}$ on parabolic dish at $21.8^{\circ} \mathrm{C}$ temperature. This research concluded that the design and function of the prototype is proven to be efficient. Parabolic dish with single axis sun tracking mechanism upturns the magnitude of current, voltage and power of mounted solar panel is about $23.6 \%$ in compare of the static solar penal and Parabolic dish with dual axis sun tracking mechanism upturns the magnitude is about $33 \%$ in compare of the static solar penal.

\section{REFERENCES}

[1] A. Ahmed, P. Hameed, Z. A. Memon, A. K. Akhani, and P. Lohana, "Implementation of Design for efficiency enhancement of solar photovoltaic panel through parabolic solar dish tracker," $1 s t$

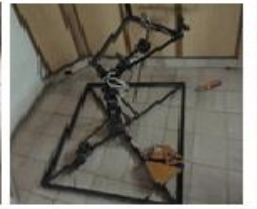

(b)Tracker frame

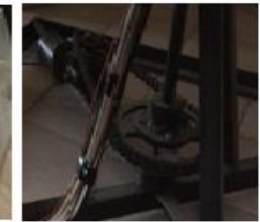

(e) 12V Power Motor

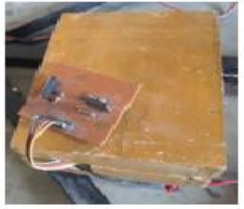

(c) controller chip

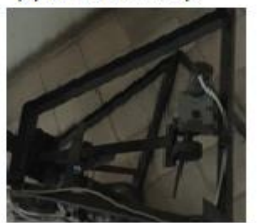

(f) $12 \mathrm{~V} \mathrm{Dc}$ Motor
Fig. 4. Prototype Parts.

International Conference on Contemporary Sociology, Social Sciences and Sustainable Development, March-2224, 2018.

[2] A. Shaikh, M. H. Kabir, I. A. Sohu , A. Ahmed, A. Ahmed Sohu "Implementation of Design for Solar Tracking system Using FPGA" International Conference On Emerging Trends In Telecommunication \& Electronic Engineering, (ICET), Feb-2728, 2018.

[3] I. Gopang, P. Hameed, and Z. A. Memon, "Parabolic dish solar system for increased power effeciency," The First International Conference on Industrial Engineering and Management Applications, (Feb-2017).

[4] K. Das, H. Ghosh, M. Sengupta, "Single Axis Solar Tracking System using Microcontroller (ATmega328) and Servo Motor," International Journal of Scientific and Research Publications, vol. 6, no. 6, June 2016.

[5] H. Hijazi ,O. Mokhiamar, and O. Elsamni, "Mechanical design of a low cost parabolic solar dish concentrator," Alexandria Engineering Journal, vol. 55, pp. 1-11, 2016.

[6] S. Danial and M. Boroushaki, "Design analysis and optimization of Solar Dish," Int. Journal of Renewable Energy.

[7] M. Navin, K. Magar, A. Abhishek, J. Fernandes, P. Kulkarni, "Solar steam 
power generator," International Conference on Technologies for Sustainable Development (ICTSD-2015), Feb. $04-06,2015$.

[8] SafaSkouri, Salwabouadila, Sassi Ben Nasrallah, "Estimating intercept factor of a solar parabolic dish with photogrammetric equipment," 6th International Renewable Energy Congress (IREC), 2015.

[9] S. Povlovic, V. Stefanovic, D. Vasiljevic, and E. Petrovic, "Optical Design of solar parabolic concentrating collector based on Trapezoidal reflective petals," Journal of energy and power Engineering, April2015.

[10] N. M. Arago, T. M. Amado, and J. W. F. Orillo, "Utilization of Cassegrain Feed Parabolic Antenna Design in Increasing the Efficiency of Photovoltaic Module," 7th IEEE International Conference humanoid, nanotechnology, information technology communication and control environment and management (HNICEM), Nov-2014.

[11] B. Anak Sup, M. Farid, T. Zanariah, R. A. Bakar, and G. Ming, "Effect of rim angle to the flux distribution diameter in solar parabolic dish collector," 2nd Int. conference on Sustainable energy engineering and Application, 2014.

[12] M. A. Soderstrand, S. B. Lee, and P. Chung, "Mini-dish based hybrid concentrated solar power system for home use," IEEE 56th Int. Midwest symposium on circuit and system (MWSCAS), Aug-2014. 